\title{
ANTERIOR CEREBRAL ARTERY, ANTERIOR COMMUNICATING ARTERY, POSTERIOR COMMUNICATING ARTERY, POSTERIOR CEREBRAL ARTERY- A RETROSPECTIVE STUDY
}

\author{
Parasa Savithri1, Teresa Rani Swamydas ${ }^{2}$ \\ 1 Professor, Department of Anatomy, Guntur Medical College affiliated to Dr. NTRUHS, Vijayawada, Andhra Pradesh. \\ ${ }^{2}$ Associate Professor, Department of Anatomy, Guntur Medical College affiliated to Dr. NTRUHS, Vijayawada, Andhra Pradesh.
}

\section{ABSTRACT}

In the embryonic period, several developmental anomalies of the cerebral arteries are common. The knowledge of these anatomical variations of the cerebral arteries is important for effective treatment and surgeries. We have studied different patterns and variations of cerebral arteries in 70 cadavers, both foetal and adult, and have depicted our observations and conclusions. "Vascular diseases in general is the commonest cause of death all over India as well as most other countries. But the diseases of blood vessels of the brain which are more frequent causes of death and disability have not attracted as much public attention as the required." 1 Hence a study of vascular supply of brain and its variational anatomy will help in proper and through understanding and interpretations of infarction embolism, thrombosis and other connected problems through modern investigation methods (Noninvasive techniques), MRI, MRA, CT and TCCD, etc. Hence, this work has been taken up, selecting the dead human foetuses and adult human cadavers.

\section{KEYWORDS}

Anterior Cerebral Artery, Communicating Artery, Posterior Communicating, Posterior Cerebral Artery.

HOW TO CITE THIS ARTICLE: Savithri P, Swamydas TR. Anterior cerebral artery, anterior communicating artery, posterior communicating artery, posterior cerebral artery- a retrospective study. J Evolution Med Dent Sci 2016;5(6):314-318, DOI: $10.14260 /$ jemds/2016/68

\section{INTRODUCTION}

The brain is supplied by the branches of internal carotid and vertebral arteries. Each Internal carotid artery gives off two major branches to the brain. These are the Anterior Cerebral Artery (ACA) and Middle Cerebral Arteries (MCA). Posterior Cerebral Artery (PCA) is a branch of basilar artery, which are formed by the union of two vertebral arteries. Posterior Communicating Artery (PCoA) from internal carotid artery joins PCA. The anterior, middle and posterior cerebral arteries give rise to two sets of branches, cortical and central. The cortical branches ramify on the surface of cerebral hemispheres and supply the cortex. The central branches pass deep into the substance of cerebral hemisphere to supply structures within it.

The present work consists of the study of the ACA, ACoA, MCA, PCoA, PCA, in Brain, both adult and foetal cadavers of Indian population.

\begin{tabular}{|c|c|}
\hline $\begin{array}{c}\text { Name of } \\
\text { the Artery }\end{array}$ & $\begin{array}{c}\text { Aspects } \\
\text { Studied }\end{array}$ \\
\hline ACA & Right and left size difference \\
\hline ACoA & $\begin{array}{c}\text { Presence or absence. Length, direction and } \\
\text { duplication }\end{array}$ \\
\hline MCA & $\begin{array}{c}\text { Fenestration, duplication and } \\
\text { quadrifurcation }\end{array}$ \\
\hline PCoA & Right and left size difference \\
\hline PCA & Right and left size difference \\
\hline
\end{tabular}

Financial or Other, Competing Interest: None.

Submission 03-12-2015, Peer Review 04-12-2015,

Acceptance 14-01-2016, Published 20-01-2016.

Corresponding Author:

Dr. Teresa Rani Swamydas,

Flat No. 403, Pooja Residency,

7/1, Chandramoulinagar,

Guntur-522007,

Andhra Pradesh, India.

E-mail: strani2k10@gmail.com

DOI:10.14260/jemds/2016/68

\section{MATERIAL AND METHODS}

Fifty dead foetuses while they were still fresh were collected from the labour room of maternity wing of Govt. General Hospital, Guntur. The age of the foetuses are calculated by crown-rump length. The length is ranging from $225 \mathrm{~mm}$ $310 \mathrm{~mm}$ and the age is roughly estimated between $20 \mathrm{wks}-38$ wks; 20 specimens of adult brains with intact vasculature are collected in Department of Anatomy, Guntur, which was kept for medical students for routine dissection.

Soon after the fresh foetuses are brought to the Department of Anatomy from Govt. General Hospital, Guntur, the following procedure is followed to remove the brain. To remove the skull cap, after the dead foetuses are placed in a tray in a supine position, a circular skin incision is given with a scissors, $1 \mathrm{~cm}$ above the eyebrows in the frontal area, running laterally and posteriorly above the ears and ending at the posterior fontanelle. With the scissors, penetrating deep to the bone in the region of pterion a cut is made in the bones along the line of skin incision as the foetal bones are thin and membranous in character. Soon after the foetal brains are taken out in the process described above, they are kept carefully in $10 \%$ formalin solution in plastic tins.

The adult brains are removed following the procedure described in Cunningham's Manual for routine dissection for medical students and preserved in 10\% Formalin solution. Dissection is performed after the Brain is fixed in preservative solution and the intracranial vascular pattern is studied carefully. Every artery is observed carefully to know the pattern and whenever it is necessary photographs are taken. After the study is over the specimens are replaced in their respective preservative solution.

\section{RESULTS}

\section{Anterior Cerebral Artery}

An enormous percentage (71.43\%) of specimens (50/70) of this study shows equality of ACA on both the sides. In 12/70 (17.14) specimens, the ACA is larger on left side. Fig 3. on right side the artery is relatively large in $8 / 70(11.43 \%)$ specimens. 
Fig 4. Heubner's artery in all the specimens of the present study, arises proximal to the fusion on both the sides. Table-1.

\section{Anterior Communicating Artery}

The present study shows that the ACoA is ranging in its length from $3 \mathrm{~mm}$ to $4 \mathrm{~mm}$ in $64 / 70$ (96\%) specimens. In 6/70 (8.5\%) specimens, the length is ranging from $1 \mathrm{~mm}$ to $2 \mathrm{~mm}$. Two adult specimens have showed double anterior communicating artery $(2 / 20,10 \%)$. Fig 1 . In 3 of the adult specimens the ACoA is obliquely placed. $(1 / 20,15 \%)$. Table- 3 . Absence of ACoA is seen in 2 adult specimens. $(2 / 20,10 \%)$. Fig 2 . The occurrence of anomalies of the ACoA in the present study in seen only in adult specimens ranging to $25 \%$. No anomalies could be seen in foetal specimens in the present study. Table -2 .

\section{Middle Cerebral Artery}

In the present study the MCA is normal in total $100 \%(70 / 70)$ specimens. We have noticed fenestration in $1 \%$, duplication in $1 \%$, accessory MCA in $2 \%$, quadrifurcation in $4 \%$ of cases.

\section{Posterior Communicating Artery}

PCoA in the present study is equal on both sides $46 / 70$ (65.71\%) specimens. The left side PCoA is larger in $14 / 70$ (20\%), specimens. Fig 3. In only 6/70 (8.5\%), specimens the PCoA is larger on right side. Fig 5. A string like artery in the current study could be observed on the left side of one adult specimen $1 / 70$ (1.43\%), Fig 6. The PCoA in this study is absent in $3 / 70$ (4.29\%), specimens. Fig 5. Out of these, 3 and 2 are foetal and one is of adult. Out of the above said 3 specimens, 2 specimens have absence of PCoA on left side and one specimen has on right side. Present study has $34.29 \%$, (24/70) specimens of total anomalies. Table- 4 .

\section{Posterior Cerebral Artery}

In the present study is equal on both the sides in a majority of the specimens, i.e., $47 / 70$ (67.14\%). On the right side the PCA is larger in $15 / 70(21.43 \%)$ specimens. Fig 6 . on the left side it is larger in $7 / 70$ (10\%), specimens. Fig 2. In 2/70 specimens $(2.86 \%)$ the PCA is arising from ICA. In one of these specimens, the PCA is on the right side (3\%) and the other is on the left side. Table-5.

\begin{tabular}{|c|c|c|c|c|}
\hline & $\begin{array}{c}\text { No. of } \\
\text { Specimens }\end{array}$ & $\begin{array}{c}\text { Right } \\
\text { Large }\end{array}$ & $\begin{array}{c}\text { Left } \\
\text { Large }\end{array}$ & Equal \\
\hline Adult & 20 & 1 & 4 & 15 \\
\hline Foetal & 50 & 7 & 8 & 35 \\
\hline \multicolumn{5}{|c|}{ Table 1 } \\
\hline
\end{tabular}

The following table and adjacent bar diagram show the presence or absence or otherwise anterior communicating artery.

\begin{tabular}{|c|c|c|c|c|c|}
\hline & $\begin{array}{c}\text { No. of } \\
\text { Specimens }\end{array}$ & Presence & Absence & Single & Double \\
\hline Adult & 20 & 18 & 2 & 16 & 2 \\
\hline Foetuses & 50 & 50 & 0 & 50 & 0 \\
\hline \multicolumn{5}{|c|}{ Table 2 } \\
\hline
\end{tabular}

\begin{tabular}{|c|c|c|c|c|}
\hline & $\begin{array}{c}\text { No. of } \\
\text { Specimens }\end{array}$ & $\begin{array}{c}\text { Normal / } \\
\text { Horizontal }\end{array}$ & Absence & $\begin{array}{c}\text { Abnormal/ } \\
\text { Oblique }\end{array}$ \\
\hline Adult & 20 & 15 & 2 & 3 \\
\hline Foetuses & 50 & 50 & 0 & 0 \\
\hline \multicolumn{2}{r|}{ Table 3: Direction of Anterior Communication Artery } \\
\hline
\end{tabular}

The following table and pie diagram show the Presence and Absence of Posterior Communicating Artery.

\begin{tabular}{|c|c|c|c|}
\hline & No. of Specimens & Presence & Absence \\
\hline Adult & 20 & 19 & 1 \\
\hline Foetuses & 50 & 48 & 2 \\
\hline \multicolumn{3}{|c|}{ Table 4 } \\
\hline
\end{tabular}

\begin{tabular}{|c|c|c|c|c|}
\hline \multirow{2}{*}{\begin{tabular}{c}
\multirow{2}{*}{$\begin{array}{c}\text { No. of } \\
\text { Specimens }\end{array}$} \\
\cline { 4 - 5 } Equal
\end{tabular}} & $\begin{array}{c}\text { Right } \\
\text { Large }\end{array}$ & $\begin{array}{c}\text { Left } \\
\text { Large }\end{array}$ \\
\cline { 3 - 5 } Adult & 20 & 12 & 3 & 5 \\
\hline Foetal & 50 & 36 & 12 & 2 \\
\hline \multicolumn{3}{|c}{ Table 5: The size of posterior cerebral artery }
\end{tabular}

Comparison of the total percentages of anomalies in posterior communicating arteries with the earlier authors.

\begin{tabular}{|c|c|c|}
\hline & Percentage & $\begin{array}{c}\text { Equal / Lesser / } \\
\text { Greater }\end{array}$ \\
\hline Present study & $34.29 \%$ & --- \\
\hline Jain P. N. 1990 & $50 \%$ & $>$ \\
\hline $\begin{array}{c}\text { Puchadas orts. A } \\
\text { 1976 }\end{array}$ & $58 \%$ & $>$ \\
\hline \multicolumn{2}{|c|}{ Table 6 } \\
\hline
\end{tabular}

\begin{tabular}{|c|c|c|c|c|c|c|c|c|}
\hline & \multicolumn{4}{|c|}{ Adult } & \multicolumn{4}{|c|}{ Foetal } \\
\hline & \multicolumn{2}{|c|}{ Absent } & \multicolumn{2}{|c|}{ String Like } & \multicolumn{2}{|c|}{ Absent } & \multicolumn{2}{|c|}{ String Like } \\
\hline & Right & Left & Right & Left & Right & Left & Right & Left \\
\hline Present study & $5 \%$ & $5 \%$ & -- & $5 \%$ & $2 \%$ & -- & -- & -- \\
\hline Earlier studies & - & - & - & - & - & - & - & - \\
\hline Jayasri N and Sadasivan G. 1981 & \multicolumn{2}{|c|}{$2 \%$} & \multicolumn{2}{|c|}{$9 \%$} & \multicolumn{2}{|c|}{--} & \multicolumn{2}{|c|}{--} \\
\hline Vare A.M. \& Bansal P.C. 1970 & \multicolumn{2}{|c|}{--} & \multicolumn{2}{|c|}{$11.7 \%$} & \multicolumn{2}{|c|}{--} & \multicolumn{2}{|c|}{--} \\
\hline Fawcett E and Blackford J.D. 1905 & \multicolumn{2}{|c|}{$3.9 \%$} & \multicolumn{2}{|c|}{--} & \multicolumn{2}{|c|}{--} & \multicolumn{2}{|c|}{--} \\
\hline Ronald A. Bergman et al. 2000 & \multicolumn{2}{|c|}{$3.09 \%$} & \multicolumn{2}{|c|}{--} & \multicolumn{2}{|c|}{--} & \multicolumn{2}{|c|}{--} \\
\hline Alpar B.J. and Berry R.G. 1963 & \multicolumn{2}{|c|}{$0.6 \%$} & \multicolumn{2}{|c|}{--} & \multicolumn{2}{|c|}{--} & \multicolumn{2}{|c|}{--} \\
\hline Windi 1888 & \multicolumn{2}{|c|}{$12.5 \%$} & \multicolumn{2}{|c|}{--} & \multicolumn{2}{|c|}{--} & \multicolumn{2}{|c|}{--} \\
\hline Stopfords 1917 & \multicolumn{2}{|c|}{$7 \%$} & \multicolumn{2}{|c|}{--} & \multicolumn{2}{|c|}{--} & \multicolumn{2}{|c|}{--} \\
\hline
\end{tabular}


The Posterior Cerebral Artery arising from ICA comparative statement

\begin{tabular}{|c|c|c|}
\hline & $\begin{array}{c}\text { PCA } \\
\text { from } \\
\text { ICA }\end{array}$ & $\begin{array}{c}\text { Comparison } \\
\text { whether equal / } \\
\text { more / less }\end{array}$ \\
\hline Present Author & $2.86 \%$ & \\
\hline Earlier studies: & & $>$ \\
\hline Sundarland S. 1948 & $32 \%$ & $>$ \\
\hline $\begin{array}{c}\text { Alpar B.J \& Berry } \\
\text { R.G. 1963 }\end{array}$ & $15 \%$ & $>$ \\
\hline $\begin{array}{c}\text { Vere A.M. \& Bensol } \\
\text { P.C. 1970 }\end{array}$ & 25 & $>$ \\
\hline Macchi C 1996 & 13 & $>$ \\
\hline $\begin{array}{c}\text { Puchades Orts A. et } \\
\text { al 1976 }\end{array}$ & $11.29 \%$ & $>$ \\
\hline $\begin{array}{c}\text { Prasad J. \& Lal RLP } \\
\text { 1970 }\end{array}$ & $8.7 \%$ & Table 8 \\
\hline \multicolumn{2}{|c|}{} \\
\hline
\end{tabular}

\begin{tabular}{|c|c|c|c|c|c|}
\hline & $\begin{array}{c}\text { No. of } \\
\text { Specimens }\end{array}$ & \multicolumn{2}{|c|}{ Normal } & \multicolumn{2}{c|}{ Abnormal } \\
\hline & & No. & $\%$ & No. & $\%$ \\
\hline Adult & 20 & 15 & $75 \%$ & 5 & $25 \%$ \\
\hline Foetal & 50 & 48 & $96 \%$ & 2 & $4.6 \%$ \\
\hline \multicolumn{6}{|c|}{ Table 9 } \\
\hline
\end{tabular}

The above abnormalities have been tabulated here in the following table.

\section{Abnormal circles of Willis}

\begin{tabular}{|c|c|}
\hline Total no. of abnormal circles & 7 \\
\hline Absence of anterior communicating artery & 2 \\
\hline Double anterior communicating artery & 2 \\
\hline Absence of posterior communicating artery & 3 \\
\hline Table 10 \\
\hline
\end{tabular}

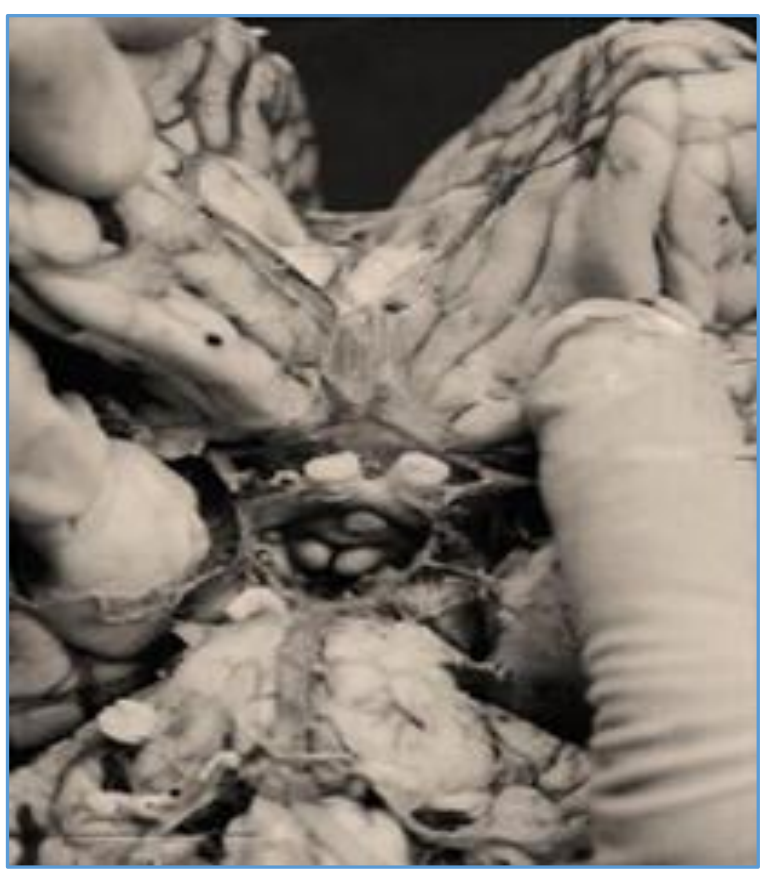

Fig. 1: Double anterior communicating

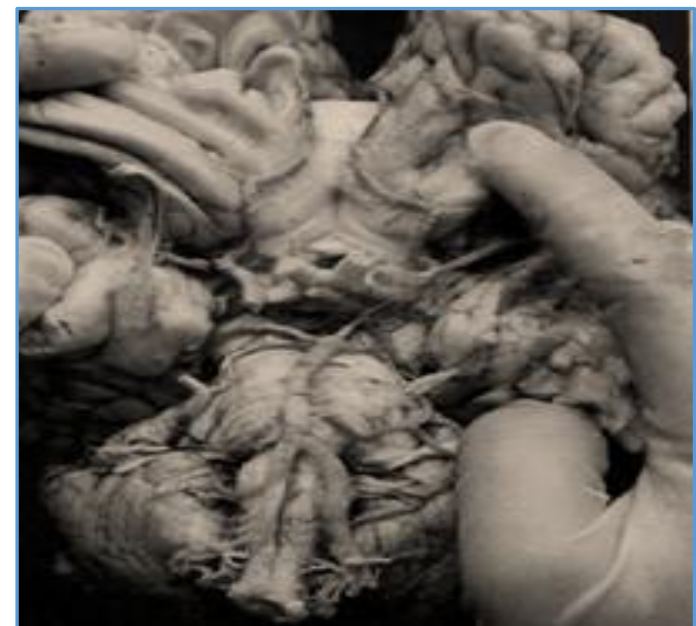

Fig. 2: Absence of anterior artery communicating artery

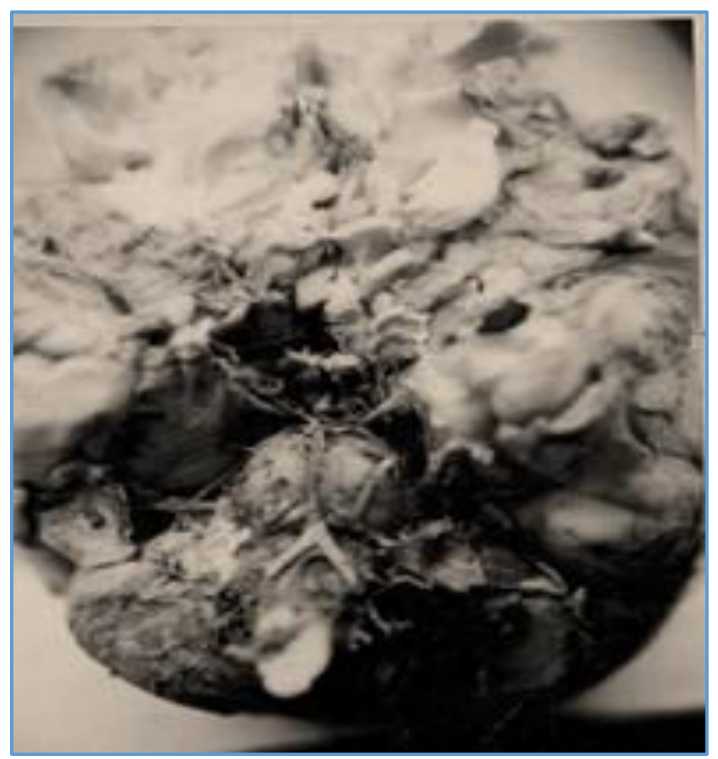

Fig. 3: Left ACA is larger

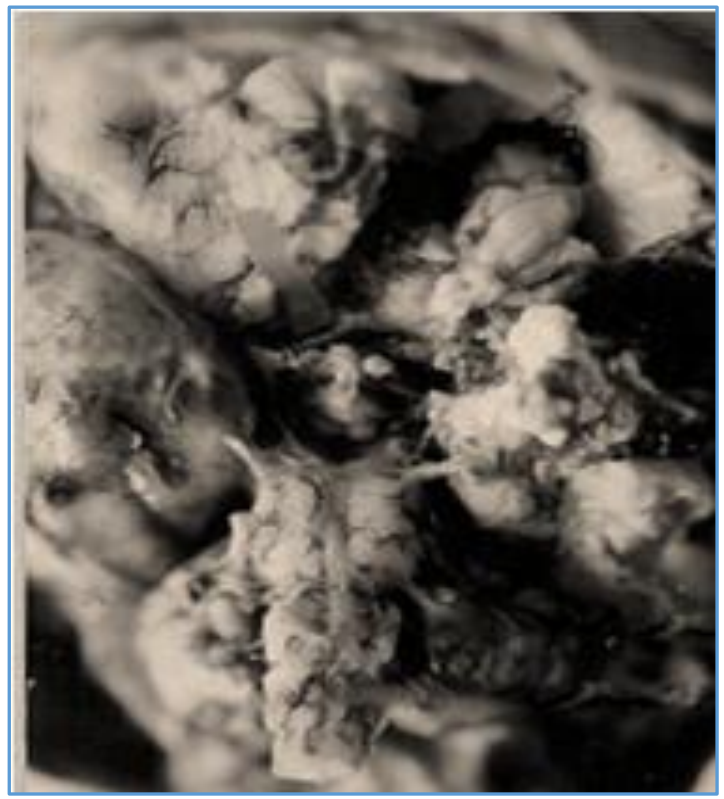

Fig. 4: Right ACA is larger 


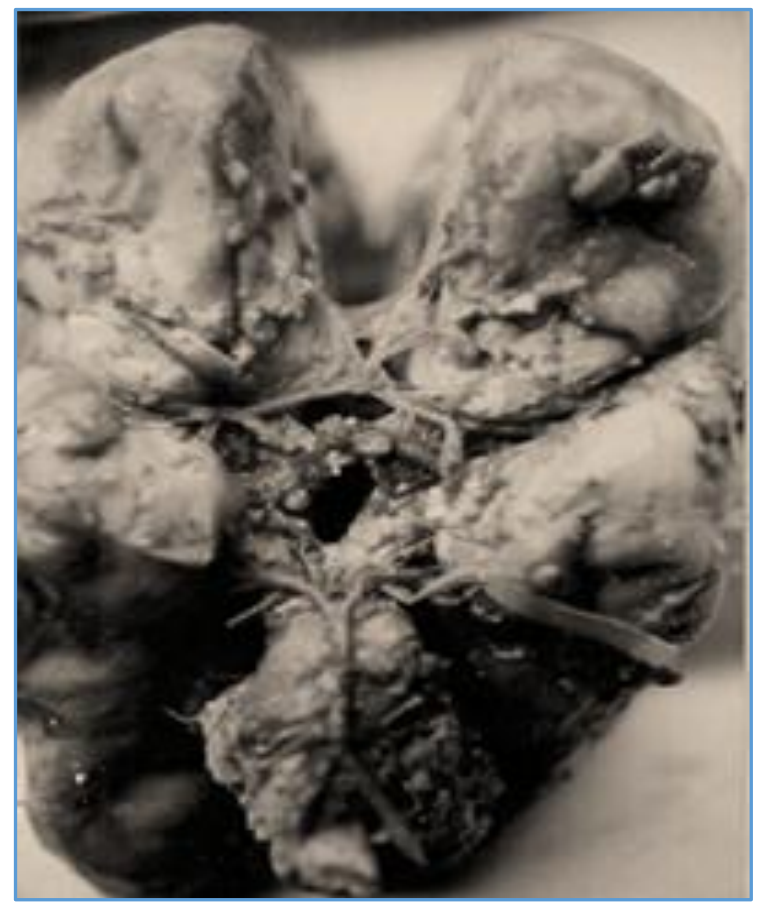

Fig. 5: Absence of posterior

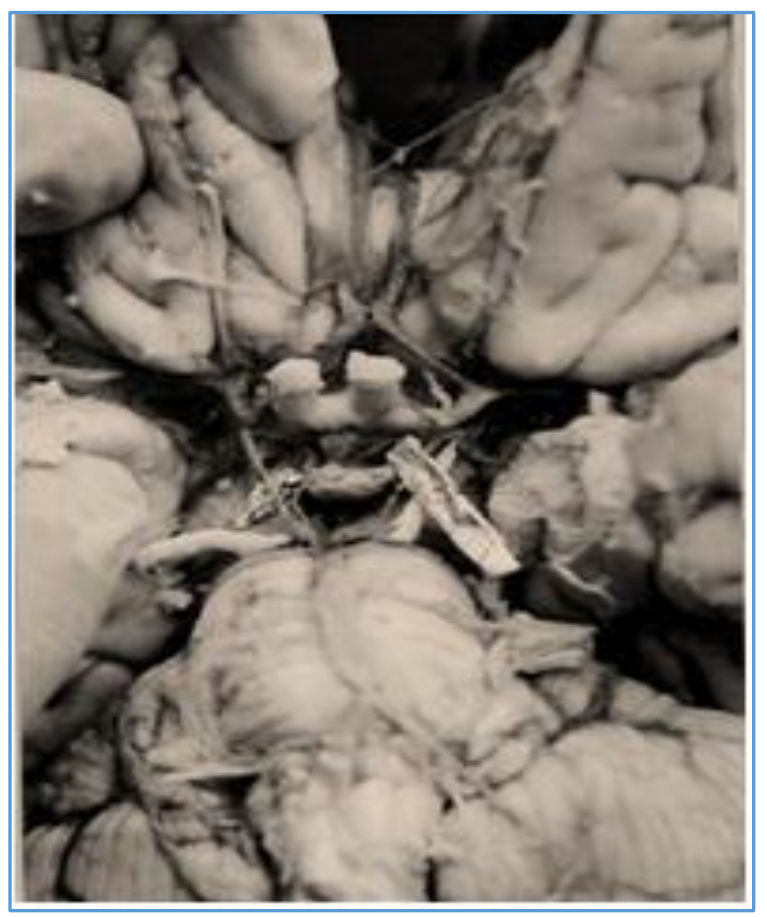

Fig. 6: String like posterior communicating artery communicating artery

\section{DISCUSSION}

\section{Anterior Cerebral Artery}

An enormous percentage (71.43\%) of specimens (50/70) of this study shows equality of ACA on both the sides. In 12/70 (17.14) specimens, the ACA is larger on left side. On right side the artery is relatively large in $8 / 70(11.43 \%)$ specimens. The arteries of the left side appear to be larger than those of the right side. ${ }^{2}$ The findings of the present study regarding these variations are similar to the observations of Lee R.M. 1995 who noticed the underdevelopment of one of the two arteries. ${ }^{3}$ The two anterior cerebral arteries frequently differ in size at their origin and the larger one reinforces the other through anterior communicating artery. ${ }^{4}$ Heubner's artery in all the specimens of the present study arises proximal to the fusion on both the sides. According to present study neither absence nor duplication nor any other sort of anomaly could have been observed. This phenomenon is dissimilar to the studies of Ronald Bergman who noticed infrequent variations, i.e. duplication of the A-1 segment and a third or medium ACA arising from the ACoA. ${ }^{4}$ Similarly, the present study also varies from the congenital absence of ACA in $1 \%$ cases on one side. 5

The present study shows that the ACoA is ranging in its length from $3 \mathrm{~mm}$ to $4 \mathrm{~mm}$ in $64 / 70$ (96\%) specimens. In 6/70 $(8.5 \%)$ specimens, the length is ranging from $1 \mathrm{~mm}$ to $2 \mathrm{~mm}$. The ACoA is usually between $2 \mathrm{~mm}$ to $3 \mathrm{~mm}$ in length, but may vary from $0.3 \mathrm{~mm}$ to $7 \mathrm{~mm}$ giving a wide range of variation in length. 4 Two adult specimens have showed double anterior communicating artery $(2 / 20,10 \%)$, in agreement with. $4,6,7,8,9$ In 3 of the adult specimens the ACoA is obliquely placed, in similarity to the findings of Esra Gurdal 2004. $(1 / 20,15 \%){ }^{6}$ Absence of ACoA is seen in 2 adult specimens; $(2 / 20,10 \%)$ on par with the findings of. $4,6,7,8,9$ The occurrence of anomalies of the ACoA in the present study in seen only in adult specimens ranging to $25 \%$ similar to. ${ }^{6,10}$

\section{Middle Cerebral Artery}

The variations of the MCA in the present study is normal in total $100 \%(70 / 70)$ specimens similar to. ${ }^{11}$ Contrary to the findings of Umansky $\mathrm{F}$ et al.1998. ${ }^{12}$ who noticed fenestration in $1 \%$, duplication in $1 \%$ accessory MCA in $2 \%$, quadrifurcation in $4 \%$ cases, we have not noticed any such variations or anomalies in our studies.

\section{Posterior Communicating Artery}

The left side PCoA is larger in 14/70 (20\%), specimens. Fig no. 2 . The arteries of the left side appeared most commonly to be larger than those of the right ones. ${ }^{2}$ the left PCoA had been often fully developed and the right ones underdeveloped. ${ }^{4}$ In accordance with the standard text books, Gray's Anatomy and Last's Anatomy, the two PCoA's, i.e. the left one and the right one are often unequal in size. A string like artery in the current study could be observed on the left side of one adult specimen $1 / 70(1.43 \%)$, in relevance to. ${ }^{13,14,15}$ The PCoA in this study is absent in 3/70 (4.29\%), specimens. Out of these, 3 and 2 are foetal and one is of adult. This observation is having a close relevance to.1,4,7,15,16 Out of the above said 3 specimens, 2 specimens have absence of PCoA on left side and one specimen has on right side. The present study has $34.29 \%(24 / 70)$ specimens of total anomalies similar to. ${ }^{10,17}$

\section{Posterior Cerebral Artery}

On the right side the PCA is larger in $15 / 70$ (21.43\%) specimens. On the left side it is larger in $7 / 70(10 \%)$, specimens. The above said right and left parameters are in inverse relationship with PCoA in cohesion with. ${ }^{14}$ In $2 / 70$ specimens (2.86\%), the PCA is arising from ICA. In one of these specimens, the PCA is on the right side (3\%). In this context, the present study is giving a wide range of deviation from the earlier authors.1,16,17,18,19 in whose observations the PCA arose from ICA ranging from $8 \%$ to $32 \%$.

\section{CONCLUSION}

However, the brief understanding is the total abnormalities and variations in the different arteries which have been 
discussed so far reveals that these abnormalities and variations are more or less relatively equal in foetal and adult specimens. Hence, this aspect of observation can be identified with that of Baptista A.G. ${ }^{20}$ 1964, who said "there is no significant difference between a child and adult intracranial arteries of the brain."

\section{REFERENCES}

1. Prasad J, Lal RLP. "Congenital abnormalities of circle of Willis." J Anat Soc of India. vol.19, 48, 1970.

2. Orlandini GE, Ruggiero C, Orlandimi S2, et al.: "Brain weight decreases with aging, the arteries of the left side appear to be larger than the right ones anarchic pattern of PCoA." 1 Acto Avet (Basel) 123(1) 72-6. NCBI: (internet page 1 or 1 ), 1985.

3. Lee R.M.: "Morphology of cerebral arteries" 1; Pharmacol ther, April 66 (1) 149-73. NCBI (Internet), 1995.

4. Ronald A Bergman, Adel K Afifi, Ryosuke MS, et al.: "Fourteen variations of circle of Willis and related vessels" Arch Pathol 75:45-64, 1963.

5. Oomman A, Madhusudhanam M: "A case of unpaired anterior cerebral artery occlusion producing akinetic mutism." Neurol India, 47:157-8 NCBI (Internet), 1999.

6. Esra Gurdal, Ozgur Cackmak, Mine Yalcinkaya, et al.: "Two variations of the anterior communicating artery a clinical reminder" Neuro-anatomy (2004) volume 3, Pages 32, 34. Published online 2 August @ neuroanatomy.org (internet), 2004.

7. Hollinshead Henry W.: "PCA arising from ICA represents foetal condition, variations in the sizes of the vessels of circle of Willis, variations in the ACoA Anatomy for surgeons," $1^{\text {st }}$ Edu Vol 1 (head and neck) 32-40, Pub: medical book department of Harper \& Brothers, New York, 1961.

8. Jayaraj L and Kalavathy TR: "The study of the variations of the arteries of Human Brain, in reference to South Indian population," J Anat soc India 51(1):97-142, (internet) Abstracts of papers $49^{\text {th }}$ conference page 99, 2002.
9. Mira L Katz: "Transcranial Colour Doppler Imaging (TCDI) National Stroke Association," retrieved April from www.stroke.org.CME (internet), 2003.

10. Jain PN, Kumar V, Thomas RJ, et al.: "Anomalies of human cerebral arterial circle (of Willis)." Journal of the Anatomical society of India, Dec; 39(2):137-46. Extracted from Ind Med Page 1 of 1 (internet), 1990.

11. Nicolos Sgarbi Lopez, Humberto Prinzoyamurri, Victor R, et al.: "Arteria cerebral media accessoria" Arch Neurophysician July/Sep. vol. 7, No. 3, ISSN 0187-4705 (internet), 2002.

12. Umansky F, Dujovny M, Ausman JI, et al.: "Anomalies and variations of the Middle Cerebral Artery: a microanatomical study." Neurosurgery Jun: 22 (6 pt. 1): 1023-7, 1988.

13. Battacharya SK, Hutchinson EC, McCall AJ: "The Circle of Willis, the incidence of abnormalities in normal infarcted brains." Brain 90(4):747-758, 1967.

14. Raja Reddy D, Prabhakar V, Dayanand Rao B: "Anatomical study of circle of Willis." Neurology India vol. 20(1):8-12, 1972.

15. Jayasree N, Sadasivan G: "Variations of circle of Willis." J Anat Soc India, vol. 30(2):72-77, 1981.

16. Alpar BJ and Berry RG. "Absence of PCoA and the circle of Willis in cerebral vascular diseases." Arch Neurol 8, 398402, 1999 cited: Esra Gurdal et al. 2004 (internet).

17. Puchades Orts A, Gomez Nombela N, Pacheco Ortuno G: "Variations in form of circle of Willis, some anatomical and embryological considerations." Anat Rec May vol. 185/1:119-123, 1976.

18. Sunderland S: "Neurovascular relation and anomalies at the base of brain." J Neurol Neurosurg and Psychiat 11:243, 1948.

19. Macchi C, Catinic, Federico C, et al.: MRA evolution of circle of Willis: "A morphologic study in human healthy subjects." Ital J Anat embryo Apr-June 101(2):115-23 NCBI (internet), 1996.

20. Baptista AG. "Studies on the arteries of the brain: III circle of Willis: Morphologic features.” Acta Neurol Scand 40(4), 398-414, 1964. 